\title{
TINDAK TUTUR ILOKUSI GURU DAN SISWA DALAM PROSES PEMBELAJARAN BAHASA INDOENSIA KELAS VIII PK DI MTSN 3 BOYOLALI TAHUN AJARAN 2018/2019
}

\author{
Novita Nurul Halimah, Farida Yufarlina Rosita \\ IAIN Surakarta \\ Email: novita.nurha@gmailcom
}

\begin{abstract}
This study reviews the illocutionary acts of teachers and students in the learning process of Indonesian Language class VIII PK in MTsN 3 Boyolali. This study aims to (1) describe the illocutionary acts of teachers and students in the VIII PK Indonesian Language learning process in MTsN 3 Boyolali, and (2) the purpose of the illocutionary speech acts of teachers and students in learning Indonesian VIII PK class at MTsN 3 Boyolali. This type of research is descriptive qualitative. The research techniques used in this study were competent listening and recording techniques. The data collection techniques are used by researchers to obtain comprehensive data regarding the types of speech acts of illocution during the learning process. Data analysis techniques in research using interactive model analysis consisting of four channels, namely, data collection, data reduction, data presentation, and drawing conclusions / verification. The results of this study found 78 data illocutionary speech acts according to Austin consisting of 6 vermiculative speech acts, 68 exclusive speech acts, and 4 commissive speech acts. The speech acts found have different goals and factors in speaking according to the situation and context. Every communication will succeed if the speaker understands the intentions of the speaker."
\end{abstract}

Keywords: Speech Acts, Illocution, Indonesian Language Learning

\section{PENDAHULUAN}

Sebagai makhluk sosial, manusia tidak bisa terlepas dari kegiatan berinteraksi dan berkomunikasi dengan menggunakan bahasa. Dalam berkomunikasi dan berinteraksi, bahasa merupakan elemen yang sangat penting. Selain itu, bahasa juga berperan penting bagi aktivitas manusia seperti penelitian, penyampaian pikiran, maupun mengungkapkan perasaan. Misalnya ketika seorang hendak menyampaikan pendapat dalam musyawarah, pasti ia akan menggunakan bahasa dalam penyampaiannya. Bahasa juga berperan penting dalam kancah pendidikan, terutama dalam kegiatan pembelajaran, khususnya pembelajaran bahasa Indonesia. Pada bidang pedidikan, bahasa digunakan untuk berkomunikasi antara guru dengan siswa, siswa dengan guru, maupun siswa dengan siswa. Bahasa dalam pendidikan digunakan untuk menyampaikan informasi dan pemikiran yang berkaitan dengan pembelajaran. Selain itu bahasa juga digunakan untuk mengetahui maksud dan tujuan dari tuturan.

Bahasa banyak dikaji dengan berbagai ilmu, salah satu cabang ilmu yang mengkaji bahasa adalah pragmatik. Pragmatik merupakan cabang ilmu yang mengkaji makna dalam 
suatu tuturan berdasarkan makna si penutur. ${ }^{1}$ Menurut Yule pragmatik adalah ilmu yang mengkaji suatu makna "yang tidak terlihat", atau dengan kata lain pragmatik adalah ilmu yang mengkaji bagaimana seseorang mengetahui apa yang dimaksud oleh mitra tutur sedangkan makna sebenarnya kata tersebut tidak dikatakan atau ditulis secara langsung. ${ }^{2}$ Dengan kata lain pragmatik merupakan ilmu yang mengkaji makna yang tidak diucapkan dalam suatu tuturan.

Dalam pragmatik ketika mengkaji suatu makna, maka seorang juga harus memperhatikan situasi ketika terjadi suatu tuturan. Tindak tutur merupakan kemampuan seorang dalam menggunakan bahasa untuk menyampaikan pesan kepada mitra tutur. Yule membagi tindak tutur dalam tiga jenis, yaitu tindak tutur lokusi, ilokusi, dan perlokusi. ${ }^{3}$ Menurut Gunawan dalam Sulistyo tindak lokusi adalah tindak tutur yang bertujuan untuk menyatakan sesuatu. ${ }^{4}$ Tindak ilokusi adalah tindak tutur yang mengandung maksud dan fungsi dalam tuturan. Tindak perlokusi merupakan tindak tutur yang pengujaranya bertujuan untuk mempengaruhi mitra tutur. ${ }^{5}$ Searle dalam Nadar, mengembangkan hipotesis bahwa pada dasarnya semua ucapan mengandung arti untuk melakukan tindakan, dan bukan hanya tuturan yang mempunyai kata kerja performantif. ${ }^{6}$ Selain itu, unsur yang paling kecil dalam komunikasi ialah tindak tutur, seperti mengatakan sesuatu, membuat pertanyaan, menguraikan, memberi perintah, menjelaskan, meminta maaf, berterima kasih, mengucapkan selamat, dan sebagainya.

Menurut Yule ada empat hakikat pragmatik, yaitu: (1) ilmu yang menelaah maksud penutur; (2) ilmu yang menelaah makna berdasarkan konteks; (3) ilmu yang mengkaji makna melebihi kajian tentang makna, yaitu menelaah makna yang dikomunikasikan dan terkomunikasikan; (4) ilmu yang mengkaji bentuk ekspresi berdasarkan jarak sosial penutur dalam suatu peristiwa tutur. ${ }^{7}$ Leech mengatakan bahwa pragmatik ialah kajian mengenai makna yang berkaitan dengan situasi ujar (speech situations) yang meliputi konteks, tujuan, unsur sapaan, waktu, tempat, tindak ilokusi, dan tuturan. ${ }^{8}$

Teori tindak tutur menurut Austin dalam Sulistyo, dibedakan menjadi tiga macam, yaitu tindak tutur locution, illocution, dan perlocution. ${ }^{9}$ Tindak tutur locution adalah tuturan yang disampaikan kepada mitra tutur dan mempunyai makna yang sistematis ditunjukkan kepada

\footnotetext{
${ }^{1}$ Woro. Retnaningsih, Kajian Pragmatik Dalam Studi Linguistik. (Yogyakarta: CV Hidayah., 2014).

${ }^{2}$ George. Yule, Kajian Bahasa (Yogyakarta: Pustaka Pelajar., 2015).

${ }^{3}$ Yule.

${ }^{4}$ Edy Tri. Sulistyo, Pragmatik: Suatu Kajian Awal. (Surakarta: UNS Press., 2013).

${ }^{5}$ Sulistyo.

${ }^{6}$ FX. Nadar, Pragmatik \& Penelitian Pragmatik. (Yogyakarta: Graha Ilmu., 2013).

${ }^{7}$ George. Yule, Pragmatik. (Yogyakarta: Pustaka Pelajar., 2014).

${ }^{8}$ Geoffrey. Leech, Prinsip-Prinsip Pragmatik. Penerjemah MD. (Jakarta: Universitas Indonesia., 1993).

${ }^{9}$ Sulistyo, Pragmatik: Suatu Kajian Awal.
} 
mitra tutur. ${ }^{10}$ Menurut Gunarwan dalam Sulistyo, tindak lokusi adalah tuturan yang bertujuan hanya untuk memberikan informasi kepada mitra tutur dan tidak memiliki makna tertentu dalam penyampaiannya. ${ }^{11}$ Tindak ilokusi yaitu tururan yang mengandung fungsi dan maksud tertentu dalam penuturannya. Tindak perlokusi adalah tindak tutur yang bertujuan untuk mempengaruhi mitra tutur.

Austin mengelompokkan tindak tutur ilokusi menjadi lima, yaitu verdiktif, eksersitif, komisif, behavitif, dan ekspositif. ${ }^{12}$ Verdiktif (verdictive), merupakan tindak tutur yang berkaitan tentang kebenaran suatu kejadian, Eksersitif (Exercitives), merupakan tindakan yang terjadi karena adanya hak, kekuasaan, dan pengaruh, Komisif (commissive), merupakan tindak tutur yang menyebabkan penutur melakukan sesuatu, misal adanya perjanjian, Behavitif (Behavitives), merupakan tindak tutur yang mencermikan rasa simpati dan rasa kepedulian, Ekspositif (Expositives), merupakan tindak tutur yang dilakukan untuk menyederhanakan istilah menjadi lebih sederhana dan mudah dimengerti.

Pada penelitian ini, peneliti memfokuskan penelitian pada tindak tutur ilokusi karena menurut peneliti tindak tutur ilokusi sangat berkaitan dengan pembelajaran, khususnya bahasa Indonesia. Selain itu, tindak tutur ilokusi juga mempunyai maksud dalam penyampaian tuturan sesuai konteks yang terjadi. Austin mengelompokkan tindak tutur ilokusi menjadi lima yaitu verdiktif, eksersitif, komisif, behavitif, dan ekspositif.

Terjadinya peristiwa tutur tentunya tidak terlepas dari interaksi yang melibatkan beberapa pihak, yaitu penutur dan mitra tutur, dalam tempat dan situasi tertentu. Proses pembelajaran di sekolah adalah salah satu contoh tempat terjadinya peristiwa tutur, dalam kegiatan belajar mengajar tentunya terjadi interaksi antara guru dan siswa atau sebaliknya. Interaksi yang terjadi dalam proses belajar mengajar bahasa Indonesia antara guru dengan siswa dan siswa dengan guru, menimbulkan tuturan-tuturan yang sangat bervariasi.

Berdasarkan uraian tersebut peneliti tertarik untuk meneliti bagaimana tindak tutur ilokusi dalam proses pembelajaran bahasa Indonesia antara guru dan siswa pada kelas VIII PK di MTsN 3 Boyolali. Berdasarkan observasi yang telah dilakukan peneliti di sekolah tersebut, peneliti menemukan terjadinya tindak tutur ilokusi antara guru dengan siswa dan siswa dengan guru dalam pembelajaran bahasa Indonesia kelas VIII PK yaitu berupa tindak verdiktif yang

\footnotetext{
10 Sulistyo.

${ }^{11}$ Sulistyo.

12 J. L. Austin, How To Do Things With Words: The William James Lectures Delivered at Harvard University in 1955. (Oxford: The Clarendon Press., 1962).
} 
berupa prasangka guru pada muridnya, tindak eksersitif yang berupa guru meminta murid untuk mengerjakan tugas, dan tindak tutur komisif yang berupa berjanjian.

Tujuan penelitian ini mendeskripsikan tindak tutur ilokusi guru dan siswa yang muncul dalam pembelajaran bahasa Indonesia kelas VIII PK di MTsN 3 Boyolali, serta mendeskripsikan tujuan tindak tutur ilokusi yang diujarkan oleh guru dan siswa dalam proses pembelajatan bahasa Indonesia kelas VIII PK di MTsN 3 Boyolali. Penelitian ini diharapkan dapat menjadi referensi atau masukan bagi perkembangan ilmu bahasa dan menambah kajian ilmu bahasa khususnya ilmu kajian pragmatik, khususnya jenis tindak tutur ilokusi. Manfaat praktis dalam penelitian ini diharapkan dapat memberikan informasi khususnya bagi pembaca yang berhubungan dengan tindak tutur ilokusi, selain itu manfaat praktis bagi penelitim yakni dapat membatu para peneliti dalam memanfaatkan bahasa. Manfaat bagi pendidik, khususnya guru bahasa Indonesia, adalah dapat digunakan sebagai gambaran dan pedoman dalam mengajarkan keterampilan berbahasa khususunya berbicara yang baik dan benar kepada siswa, serta menambah pengetahuan mengenai tindak tutur dalam ilmu pragmatik.

Penelitian yand dilakukan oleh Ferdian dan Rustya ${ }^{13}$ dapat dikatakan relevan dengan penelitian ini. sayangnya, penelitian yang dilakukan oleh Ferdian dan Rustya hanya menguraikan bentuk tindak tutur tanpa mendeskripsikan lebih dalam mengenai tujuan dari tuturan tersebut. penelitian tersebut hanya menguraikan bentuk tindak tutur lokusi, ilokusi dan perlokusi dalam talk show the interview with tukul. perbedaan dengan penelitian tersebut terletak pada objek antara talk show dengan tuturan pembelajaran di kelas. Perbedaan lainnya juga terletak pada kajian antara seluruh jenis tindak tutur yang dikaji pada penelitian tersebut dengan hanya mengkaji tindak tutur lokusi pada penelitian ini.

\section{METODE PENELITIAN}

Jenis penelitian ini adalah deskriptif kualitatif. Sumber data penelitian ini adalah transkripi tuturan guru dan siswa selama proses pembelajaran bahasa Indonesia kelas VIII PK di MTsN 3 Boyolali. Data dalam peelitian ini berupa tuturan-tuturan guru dan siswa dalam proses pembelajaran bahasa Indonesia. Teknik pengumpulan data dalam penelitian ini menggunakan teknik simak bebas libat cakap, yaitu peneliti berperan sebagai pengamat penggunaan bahasa oleh informannya. ${ }^{14}$ Selain itu peneliti juga menggunakan teknik rekaman

\footnotetext{
${ }^{13}$ Ferdian Achsani and Rustyaningsih, "Tindak Tutur Dalam Talk Show The Interview With Tukul Episode : Walikota Semarang Dan Aktor Mata Batin,” BASINDO : Jurnal Kajian Bahasa, Sastra Indonesia, Dan Pembelajarannya Volume 2, no. 2 (2018): 132-38.

${ }^{14}$ Mahsun, Metode Penelitian Bahasa: Tahapan Steategi, Metode, Dan Tekniknya, Edisi Revi (Jakarta: PT Raja Grafindo Persada, 2012).
} 
data, teknik ini digunakan agar data yang diperoleh akurat. Rekaman yang dimaksud dalam penelitian ini adalah merekam ujaran guru dan siswa selama proses pembelajaran bahasa Indonesia menggunakan handphone. Data yang direkam adalah tuturan guru bahasa Indonesia dan siswa dalam interaksi belajar mengajar di MTsN 3 Boyolali kelas VIII PK. Rekaman tuturan tersebut ditanskripkan dalam bentuk teks agar mempermudah peneliti dalam menganalisis data.

Teknik pemeriksaan keabsahan data yang digunakan dalam penelitian ini menggunakan teknik triangulasi, yaitu teknik pemeriksaan keabsahan data yang memanfaatkan sesuatu yang terlepas dari data tersebut yang digunakan untuk pendamping ataupun memeriksa kembali data yang telah didapat. ${ }^{15}$ Pada pengujian kredibilitas ini, triangulasi diartikan sebagai pemeriksaan data dari berbagai sumber dan dengan berbagai cara, dan berbagai waktu. Jadi dalam pemeriksaan keabsahan data terdapat triangulasi sumber, teknik pengumpulan data, dan waktu. ${ }^{16}$ Untuk memeriksa keabsahan data dalam penelitian ini, peneliti menggunakan teknik triangulasi teori.

Teknik analisis data yang digunakan dalam penelitian ini yaitu menggunakan model interaktif menurut Miles dan Huberman. Analisis data yang digunakan terdiri dari tiga alur kegiatan yang terjadi secara bersamaan yaitu: reduksi data, penyajian data, dan penarikan kesimpulan/ verifikasi.

\section{HASIL PENELITIAN DAN PEMBAHASAN}

Pada bagian ini akan dipaparkan mengenai data yang diperoleh dari proses pembelajaran bahasa Indonesia di kelas VIII PK 2. Data yang diambil dalam penelitian ini adalah tuturan antara guru dan siswa yang terjadi ketika proses pembelajaran bahasa Indonesia pada kelas VIII PK 2 di MTsN 3 Boyolali. Adapun jenis dan makna tindak tutur ilokusi dari proses pembelajaran bahasa Indonesia tahun ajaran 2018/2019 yang dianalisis yaitu tiga jenis tindak tutur ilokusi yang terdiri dari tindak tutur verdiktif, tindak tutur eksersitif, dan tindak tutur komisif.

Tindak Tutur Ilokusi Guru dan Siswa yang Muncul dalam Proses Pembelajaran Bahasa Indonesia Kelas VIII PK di MTsN 3 Boyolali

Tindak Tutur Verdiktif

\footnotetext{
${ }^{15}$ Burhan. Nurgiyantoro, Teori Pengkajian Fiksi (Yogyakarta: Gadjah Mada University Press., 2013).

16 Nurgiyantoro.
} 


\section{Data 1}

Guru: Berati tidak mendengarkan kamu! Itu salah soal tidak yang di LKSnya? (1)

Berdasarkan data 1, kutipan percakapan tersebut termasuk ke dalam jenis tindak tutur verdiktif. Terlihat pada tuturan guru yang menuduh siswa tidak mendengarkan pembelajaran saat bertanya mengenai soal TAB.

Data 2

Guru : Kok doraemon to? Koe ra ngrungokne to mau? Neng

pikirane eneke Nayla wae.. (2)

Berdasarkan data 2, kutipan percakapan tersebut termasuk ke dalam jenis tindak tutur verdiktif. Terlihat pada tuturan guru yang menyalahkan siswa saat ditanya oleh guru untuk menyebutkan buku fiksi.

Data 3

Guru: Berisi kata-kata sulit yang ada di situ, berdasarkan abjad.

\section{Abjad itu apa saja? Nanti jangan-jangan kalian nggak tau.. (3)}

Berdasarkan data 3, kutipan percakapan tersebut termasuk ke dalam tindak tutur verdiktif. Terlihat pada tuturan guru yang menuduh siswa tidak hafal abjad.

Dari data yang telah diapaparkan peneliti, dapat disimpulkan bahwa jenis tindak tutur verdiktif yang digunakan oleh guru memiliki tuturan yang bervariatif yang memiliki maksud sesuai dengan konteks.

\section{Tindak Tutur Eksersitif}

Data 1

\section{Guru : Hari kamis jam 6-7 bu guru ada di sini to? Nah, jam 6-7 nya} diganti jam bahasa Inggris (4)

Berdasarkan data 1, kutipan percakapan tersebut termasuk ke dalam tindak tutur eksersitif. Terlihat pada tuturan guru saat memberitahu siswa ada pergantian jam, dan menyuruh siswa untuk mempersiapkan tugas pada hari itu.

Data 2

Guru : Izin memberi pengumuman ya $\mathrm{Bu}(5)$

Guru : Iya pak, silakan (6)

Guru : Anak-anak besok kan kelas IX ada ujian, nah nanti kelasnya pindah ke kelas IX D ya (7) 
Berdasarkan data 2, percakapan tersebut termasuk ke dalam tindak tutur eksersitif. Terlihat pada tuturan guru yang mempunyai kekuasaan menyuruh siswa untuk pindah ke kelas lain karena kelasnya akan dipakai untuk ujian.

Data 3

Guru : Oke sekarang silakan ke perpustakaan! (8)

Berdasarkan data 3, kutipan percakapan tersebut termasuk ke dalam tindak tutur eksersitif. Terlihat pada tuturan guru yang mempunyai kekuasaan untuk menyuruh siswanya ke perpustakaan.

Dari data yang telah dipaparkan oleh peneliti, dapat disimpulkan bahwa jenis tindak tutur eksersitif lebih banyak digunakan oleh guru untuk memerintah siswa agar melakukan sesuatu sesuai yang diinginkannya.

\section{Tindak Tutur Komisif}

Data 1

Guru: Ya, nanti kalau di perpustakaan kalian punya tugas. Nanti cari, oh ini tho buku ensiklopedia.. Kapan-kapan ke perpustakaan daerah tapi pas di luar jam pelajaran nggak papa ya? (9)

Berdasarkan data 1, kutipan percakapan tersebut termasuk ke dalam jenis tindak tutur komisif. Terlihat pada tuturan guru yang berencana akan mengajak siswa untuk berkunjung ke perpustakaan daerah di luar jam pelajaran, dan guru juga mempunyai rencana akan memberi tugas pada siswa saat di perpustakaan.

Data 2

Guru : Kita ketemu di sana, jam berapa gitu.. jam satu.. (10)

Siswa : Hari senin ya $\mathrm{Bu}(11)$

Berdasarkan data 2, kutipan percakapan tersebut termasuk ke dalam tindak tutur komisif. Terlihat pada tuturan guru dan siswa yang berencana akan bertemu di perpustakaan daerah pada hari senin jam satu siang.

Data 3

Guru : Saya selama anak-anak kelas IX belum UN belun bisa

mendampingi ke perpus. Kalian ke simpang lima bingung? (12)

Berdasarkan data 3, kutipan percakapan tersebut termasuk ke dalam tindak tutur komisif berjanji. Terlihat dari tuturan guru yang memberitahu siswa bahwa beliau tidak bisa mengajar selama kelas IX belum melaksanakan ujian. 
Dari data yang telah dipaparkan peneliti, dapat disimpulkan bahwa jenis tindak tutur komisif yang digunakan guru maupun siswa mempunyai variari dalam menuturkannyam tentunya memiliki maksud tersendiri sesuai dengan konteks.

Tujuan Tindak Tutur Ilokusi yang Dituturkan oleh Guru dan Siswa dalam Proses Pembelajaran Bahasa Indonesia Kelas VIII PK di MTsN 3 Boyolali

\section{Tindak Tutur Verdiktif}

Data 1

Guru : Berati tidak mendengarkan kamu! Itu salah soal tidak yang di LKSnya? (1)

Berdasarkan data 1, tujuan dari kutipan percakapan tersebut adalah menyindir siswa karena tidak mendengarkan penjelasakan guru saat menjelaskan kesalahan soal yang ada di LKS.

Data 2

Guru : Kok doraemon to? Koe ra ngrungokne to mau? Neng pikirane eneke Nayla wae.. (2)

Berdasarkan data 2, tujuan dari kutipan percakapan tersebut adalah menyindir siswa karena tidak bisa menjawab pertanyaan dari guru. Selain itu secara tidak langsung guru menyuruh siswa untuk membuka buku pelajaran.

Data 3

Guru : Berisi kata-kata sulit yang ada di situ, berdasarkan abjad.

Abjad itu apa saja? Nanti jangan-jangan kalian nggak tau.. (3)

Berdasarkan data 3, tujuan dari kutipan percakapan tersebut adalah mengajak bercanda siswa dengan menuduh siswa tidak tahu huruf abjad. Dari data yang telah peneliti analisis, dapat disimpulkan bahwa jenis tindak tutur verdiktif memiliki tujuan yang bersifat heterogen. Tujuan atau makna dari tindak tutur ini berbeda-beda menurut konteks yang ada.

\section{Tindak Tutur Eksersitif}

Data 1

Guru : Hari kamis jam 6-7 bu guru ada di sini to? Nah, jam

6-7 nya diganti jam bahasa Inggris (4) 
Berdasarkan data 1, tujuan dari kutipan percakapan tersebut adalah menyuruh siswa untuk menyiapkan buku pelajaran yang akan diganti pada hari itu, selain itu agar siswa tidak kaget saat guru tersebut datang di jam yang berbeda.

Data 2

Guru : Izin memberi pengumuman ya $\mathrm{Bu}(5)$

Guru : Iya pak, silakan (6)

Guru : Anak-anak besok kan kelas IX ada ujian, nah nanti

kelasnya pindah ke kelas IX D ya (7)

Berdasarkan data 2, tujuan dari percakapan tersebut adalah memberitahu dan menyuruh siswa untuk pindah kelas saat kelas IX melaksanakan ujian, karena ruang kelas akan dipakai ujian.

Data 3

Guru : Oke sekarang silakan ke perpustakaan!(8)

Berdasarkan data 3, tujuan dari kutipan percakapan tersebut adalah menyuruh siswa untuk meminjam buku di perpustakaan untuk selanjutnya dibuat peta konsep.

Dari data yang telah peneliti analisis, dapat disimpulkan bahwa jenis tindak tutur ekserditif mempunyai tujuan yang sama yaitu memerintah mitra tutur untuk melakukan sesuatu baik secara langsung maupun tidak langsung.

\section{Tindak Tutur Komisif}

Data 1

Guru : Ya, nanti kalau di perpustakaan kalian punya tugas. Nanti cari, oh ini tho buku ensiklopedia.. Kapan-kapan ke perpustakaan daerah tapi pas di luar jam pelajaran nggak papa ya? (9)

Berdasarkan data 1, tujuan dari kutipan percakapan tersebut adalah merencanakan kegiatan yang akan dilakukan saat mengunjungi perpusda, secara tidak langsung guru menyuruh siswa untuk lebih mempersiapkan diri ketika mengunjungi perpusda.

Data 2

Guru : Kita ketemu di sana, jam berapa gitu.. jam satu.. (10) 
Siswa : Hari senin ya Bu (11)

Berdasarkan data 2, tujuan dari kutipan percakapan tersebut adalah agar siswa mempersiapkan diri pada hari senin untuk mengunjungi perpusda, dan tidak boleh terlambat.

Data 3

\section{Guru : Saya selama anak-anak kelas IX belum UN belun bisa} mendampingi ke perpus. Kalian ke simpang lima bingung?

Berdasarkan data 3, tujuan dari kutipan percakapan tersebut adalah memberitahu siswa bahwa kegiatan berkunjung ke perpusda tidak bisa dilakukan dalam waktu dekat karena kelas IX mendekati UN.

Dari data yang telah peneliti analisis, dapat disimpulkan bahwa jenis tindak tutur komisif memiliki tujuan yaitu hendak atau ingin melakukan suatu kegiatan.

\section{KESIMPULAN}

Berdasarkan hasil analisis data mengenai tindak tutur ilokusi dalam proses pembelajaran bahasa Indonesia kelas VIII PK di MTsN 3 Boyolali, peneliti dapat mengambil beberapa kesimpulan yaitu ditemukan 78 data tindak tutur ilokusi menurut Austin yang ditemukan dalam proses pembelajaran bahasa Indonesia kelas VIII PK di MTsN 3 Boyolali yang terdiri dari (1) Terdapat 6 data tindak tutur ilokusi verdiktif, 68 data tindak tutur ilokusi eksersitif, dan 4 data tindak tutur ilokusi komisif, (2) Berdasarkan data tindak tutur menutut Austin, tindak tutur yang sering digunakan dalam proses pembelajaran bahasa Indonesia yaitu tindak tutur ilokusi eksesitif. Tujuan tindak tutur ilokusi yang diujarkan oleh guru dan sisswa dalam proses pembelajaran bahasa Indonesia kelas VIII PK di MTsN 3 Boyolali yaitu setiap tuturan tidak selalu memiliki tujuan yang sama, tuturan-tuturan tersebut memiliki tujuan yang beragam sesuai situasi dan konteks yang ada. Situasi dan faktor yang menyebabkan terjadinya tindak tutur ilokusi juga berbeda-beda sesuai dengan tindak tutur yang dituturkan.

\section{DAFTAR PUSTAKA}

Achsani, Ferdian, and Rustyaningsih. "Tindak Tutur Dalam Talk Show The Interview With Tukul Episode : Walikota Semarang Dan Aktor Mata Batin.” BASINDO : Jurnal Kajian Bahasa, Sastra Indonesia, Dan Pembelajarannya Volume 2, no. 2 (2018): 132-38. Austin, J. L. How To Do Things With Words: The William James Lectures Delivered at 
Harvard University in 1955. Oxford: The Clarendon Press., 1962.

Leech, Geoffrey. Prinsip-Prinsip Pragmatik. Penerjemah MD. Jakarta: Universitas Indonesia., 1993.

Mahsun. Metode Penelitian Bahasa: Tahapan Steategi, Metode, Dan Tekniknya. Edisi Revi. Jakarta: PT Raja Grafindo Persada, 2012.

Nadar, FX. Pragmatik \& Penelitian Pragmatik. Yogyakarta: Graha Ilmu., 2013.

Nurgiyantoro, Burhan. Teori Pengkajian Fiksi. Yogyakarta: Gadjah Mada University Press., 2013.

Retnaningsih, Woro. Kajian Pragmatik Dalam Studi Linguistik. Yogyakarta: CV Hidayah., 2014.

Sulistyo, Edy Tri. Pragmatik: Suatu Kajian Awal. Surakarta: UNS Press., 2013.

Yule, George. Kajian Bahasa. Yogyakarta: Pustaka Pelajar., 2015.

Pragmatik. Yogyakarta: Pustaka Pelajar., 2014. 